\title{
PERBAIKAN PROSES KERJA MENGGUNAKAN METODE SIX SIGMA PADA BAGIAN PEMASARAN KANTOR POS BANDUNG
}

\author{
Dr. Ir. Agus Purnomo, MT. \\ Prodi D4 Logistik Bisnis Politeknik Pos Indonesia \\ aguspurnomo@poltekpos.ac.id
}

\begin{abstract}
Abstrak
Proses Kerja di bagian Pemasaran PT Pos Indonesia penting dilakukan dengan baik karena aktivitas ini berhubungan dengan pelayanan terhadap pelanggan. Saat ini banyak terdapat keluhan-keluhan dari pelanggan terkait proses kerja yang berdampak merugikan pelanggan dan juga PT Pos Indonesia. Tujuan penelitian ini adalah melakukan perbaikan proses kerja pada Bagian Pemasaran Kantor Pos Bandung dengan Metode Six Sigma dalam upaya meningkatkan pelayanan kepada pelanggan. Permasalahan yang menjadi prioritas utama untuk diperbaiki adalah Kesalahan External id pada penginputan ke Ipos-Web yang berdampak pada ketidakpuasan konsumen dan berdampak pada neraca, backsheet maupun tagihan yang akan dilakukan oleh PT Pos Indonesia. Upaya yang perlu dilakukan untuk memperbaiki Kesalahan External id yaitu : perlunya peningkatan peran Manajer dalam melakukan pengawasan kerja, perlunya briefing sebelum pekerjaan dimulai, adanya reward dan punishment untuk meningkatkan produktivitas staf, membuat daftar Kode External Id Customer yang ditempatkan di meja entri komputer, serta peningkatan kapasitas bandwith dan perluasan akses internet.
\end{abstract}

Kata Kunci: Six Sigma, External id, Customer Complaint, Improvement, DMAIC 


\section{PENDAHULUAN}

Bagian Pemasaran PT Pos Indonesia (Persero) berfungsi melakukan penawaran layanan jasa kepada mitra untuk bekerja sama, mengakuisisi pasar, mengendalikan anggaran penjualan dan penagihan piutang. Oleh karena itu, Bagian Pemasaran memiliki peran yang sangat penting dalam kegiatan bisnis PT Pos Indonesia (Persero) untuk memperoleh pendapatan dan memaksimal pelayanan kepada pelanggan. Proses Kerja di bagian Pemasaran PT. Pos Indonesia secara berurutan yaitu melakukan penawaran kerja sama dengan mitra, membuat dokumen perjanjian kerja sama, tanda tangan perjanjian kerja sama, surat dan paket di pickup oleh pengantar, penginputan data kiriman ke aplikasi ipos-web, pembukuan oleh admin penjualan, membuat surat tagihan piutang, menerima transaksi pembayaran, mencetak kwitansi, dan pembukuan di rekening koran kantor pos. Hasil identifikasi awal peneliti pada proses kerja Bagian Pemasaran Kantor Pos Bandung terdapat komplin dan kekecewaan pelanggan tentang proses kerja dimana terjadinya kesalahankesalahan pada transaksi pelayanan. Dengan demikian fokus Bagian Pemasaran adalah untuk memperbaiki proses kerja tersebut untuk meningkatkan pelayanan pelanggan dan kinerja perusahaan.

Tujuan penelitian ini adalah melakukan perbaikan proses kerja pada Bagian Pemasaran Kantor Pos Bandung dengan Metode Six Sigma dalam upaya meningkatkan pelayanan kepada pelanggan. Metode Six Sigma merupakan upaya perbaikan berkelanjutan dengan melibatkan pihak internal maupun eksternal perusahaan yang bisa bermanfaat memperbaiki proses kerja dengan berfokus pada pelanggan (Pyzdek, 2000). Six Sigma menggunakan pendekatan DMAIC (define, measurement, analyze, improve, control) yang bertujuan melakukan perbaikan secara berkelanjutan secara sistematik (Pusporini, 2009). Dalam Six Sigma bertujuan pula meningkatkan keuntungan dan nilai tambah perusahaan dengan cara menetapkan target 3.4 defect per million opportunity (DPMO) (Vanany et al., 2007). Kesalahan/cacat dalam pengertian Six Sigma adalah ketidaksesuaian atau tidak memenuhi ekspektasi dan spesifikasi pelanggan dari keluaran suatu proses operasi perusahaan (Mehrjerdi, 2011).

\section{METODE PENELITIAN}

Penelitian ini menggunakan nonsep Six Sigma dengan pendekatan DMAIC (Define, Measure, Analyze, Improvement, Control) yang merupakan tools peningkatan mutu dan perbaikan proses secara berkelanjutan dalam operasi perusahaan. Konsep DMAIC yaitu mengeliminasi kegiatan atau proses yang tidak bermanfaat atau mubazir dan menggunakan teknologi dan metoda statistik untuk perbaikan mutu dan mencapai target Six Sigma (Kumar, S., \& Sosnoski, M. , 2009).
Tahap-tahapan yang dilakukan dalam penelitian ini terdiri atas (Sokovic, et al., 2010; Sin, et al., 2015):

\subsection{Define}

Merupakan tahap awal yang dilakukan dalam six sigma untuk mengidentifikasi kecacatan layanan atau produk serta menentukan sasaran yang akan dicapai pada proses. Berikutnya ditetapkan Critical to Quality (CTQ) mengacu pada masukan pelanggan terhadap mutu jasa atau produk yang dihasilkan.

\subsection{Measure}

Measure merupakan penetapan proses internal yang menjadi kunci yang akan mempengaruhi CTQ serta dilakukan pengukuran frekuensi /jumlah data kegagalan atau ketidkasesuaian yang terjadi pada proses operasi dalam suatu perusahaan (Gaspersz, 2005). Pada tahap ini digunakan Diagram Pareto untuk menetapkan kecacatan (ketidaksesuaian) utama sebagai CTQ dan juga mengukur tingkat sigma serta nilai total DPMO.

\subsection{Analyze}

Merupakan tahap mencari dan menemukan dari akar penyebab tentang masalah yang menjadi prioritas utama yang akan diperbaiki. Tools yang digunakan pada tahap Analyze yaitu Fishbone Diagram atau Ishikawa Diagram atau Diagram Sebab Akibat. Diagram ini memperlihatkan faktor-faktor penyebab utama yang terdiri dari bahan baku (Material), Mesin (Machine), Tenaga Kerja (Man), Metode (Method), dan Lingkungan (Environment).

\subsection{Improve}

Tujuan yang hendak dicapai pada tahap improve adalah memberikan solusi-solusi untuk mencapai atau melampaui target tujuan Six Sigma dari suatu proyek perbaikan. Tahap improve mengimplementasikan pendekatan $5 \mathrm{~W}+1 \mathrm{H}$ yang terdiri atas (1) What, apa yang merupakan sasaran utama dari perbaikan mutu? (2) Why, mengapa tindakan perlu dilakukan untuk memperbaiki mutu? (3) Where, dimana akan dilaksanakan perbaikan? (4) Who, siapa saja akan terlibat melakukan kegiatan perbaikan? (5) When, kapan akan dilakukan tindakan perbaikan? (6) How, bagaimana cara melakukan tindakan perbaikan?

\subsection{Control}

Pada tahap Control dilakukan dokumentasi hasil peningkatan Six Sigma berupa dokumen peningkatan kualitas, prosedu-prosedur, dan pedoman kerja standar serta pengalihan tanggung jawab ke pelaksana proses operasi. 


\section{HASIL DAN PEMBAHASAN}

Berdasarkan hasil pengamatan pada proses kerja di Bagian Pemasaran Kantor Pos Bandung, maka dilakukan proses DMAIC sebagai berikut :

\subsection{Define}

Define adalah tahap untuk menentukan pokok permasalahan, yang diperoleh dari hasil pengamatan diperusahaan sehingga diperoleh data perm aslahan yang valid. Selanjutnya, dideskripsikan atau dijelaskan setiap permasalahan sehingga dapat ditentukan CTQ. Permasalahan yang diidentifikasi pada proses kerja di Bagian Pemasaran Kantor Pos Bandung sebagai pokok masalah adalah sebagai berikut :

\section{1) Kesalahan External ID}

Setiap customer / pelanggan Korporat mempunyai external id masing-masing, namun terkadang hal ini sering kali tidak sesuainya nama mitra dengan external id yang dimilikinya. Hal ini terjadi karena petugas yang sering salah dalam proses penginputan external id. Hal ini menyebabkan banyaknya customer complaint ke perusahaan yang disebabkan karena faktor ini. Dampak dari kesalahan external id yaitu laporan kolekting kiriman koorporat yang ada di webbase aplikasi Pos Indonesia tidak sesuai dengan nama mitra koorporatnya dikarenakan external id yang salah. Tidak hanya itu, dalam data di neraca, backsheet ataupun tagihannya juga bermasalah dan data mitra tersebut tergabung dengan mitra lainnya.

\section{2) Kesalahan Penginputan Alamat Penerima}

Kesalahan Penginputan Alamat Penerima berdampak barang salah dikirim ke alamat tujuan, sehingga customer complaint karena barang tidak sampai ke customer serta dibutuhkan waktu untuk melacak posisi barang. Dampak terhadap perusahaan akan meningkatkan biaya operasi logistik dan menurunkan kepercayaan customer terhadap layanan jasa PT. Pos Indonesia.

3) Kesalahan Penginputan Biaya Harga Tanggungan Nilai Barang (HTNB)

Harga Tanggungan Nilai Barang atau biasa disebut dengan HTNB adalah biaya pengganti yang diberikan oleh PT Pos Indonesia jika terjadi kerusakan atau kehilangan barang, dalam hal ini hamper sama dengan asuransi. Misalkan, jika barang hilang atau rusak pihak PT. Pos Indonesia bisa menggantikannya 10x lipat dengan biaya ongkos kirim. Dalam proses penginputan biaya HTNB ini sering terjadi kesalahan dalam memasukkan jumlah nominalnya, sehingga besar biaya pengganti yang diperoleh customer tidak sesuai dengan jumlah HTNB yang diinginkan customer.
4) Keterlambatan Membayar Piutang Atau Piutang Macet Keterlambatan dalam membayar piutang terkadang terjadi karena tidak balance tagihan nominal antara mitra koorporat dan PT. Pos Indonesia, dan bisa juga disebabkan oleh kesengajaan oleh customer itu sendiri. Dampak dari telat dalam pembayaran piutang ini membuat terhambatnya pendapatan, arus kas menjadi tidak lancar dan bisa mengakibatkan cash flow jika secara terus menerus.

\subsection{Measure}

Pengumpulan data pada tahap Measure dilakukan dengan menggunakan checksheet dan dilanjutkan menggunakan Pareto Diagram.

\subsubsection{Check Sheet}

Tahap awal Measure yaitu menggunakan Lembar Periksa (check sheet) yang merupakan formulir yang dirancang guna mencatat frekuensi data yang dapat menggambarkan pola data permasalahan atau kecacatan layanan. Berdasarkan pengamatan tentang proses kerja di Bagian Pemasaran Kantor Pos Bandung pada periode bulan Juni - September 2020, maka permasalahan utama yang terjadi dapat diidentifikasi frekuensinya sebagai berikut :

Tabel 1. Check Sheet Frekuensi Jenis Permasalahan di Kantor Pos Bandung

\begin{tabular}{|l|c|c|c|c|c|}
\hline \multirow{2}{*}{ Jenis Permasalahan } & \multicolumn{4}{|c|}{ Bulan(Tahun 2020) } & \multirow{2}{*}{ Total } \\
\cline { 2 - 5 } & Juni & Juli & Agustus & September & \\
\hline Kesalahan External ID & 13 & 7 & 24 & 4 & 48 \\
\hline $\begin{array}{l}\text { Kesalahan Penginputan } \\
\text { Alamat Penerima }\end{array}$ & 7 & 9 & 10 & 7 & 33 \\
\hline $\begin{array}{l}\text { Kesalahan Penginputan } \\
\text { Biaya HTNB }\end{array}$ & 4 & 4 & 7 & 2 & 17 \\
\hline Piutang Macet & 1 & 3 & 3 & 3 & 10 \\
\hline \multicolumn{1}{|c|}{ Total } & 25 & 23 & 44 & 16 & 108 \\
\hline
\end{tabular}

\subsubsection{Diagram Pareto}

Menurut (Gaspersz, 2005), Diagram Pareto menggambarkan urutan data frekuensi mulai dari frekuensi yang terbesar sampai dengan yang terkecil. Diagram Pareto memperlihatkan penyebab masalah-masalah yang paling dominan, mulai dari permasalahan yang menjadi prioritas utama dan yang bukan prioritas utama untuk diperbaiki. Pembuatan Diagram Pareto menggunakan data diskrit atau kategori dari masalah kecacatan yang telah diidentifikasi pada Check Sheet. Analisis Diagram Pareto mengacu dari "hukum 80/20", artinya bahwa 80\% ketidaksesuaian/kegagalan pada produk atau jasa pelayanan disebabkan oleh $20 \%$ masalah utama.. Langkahlangkah pembuatan Diagram Pareto terdiri dari : 
1. Tentukan klasifikasi data, misalnya berdasarkan permasalahan, penyebab, jenis ketidaksesuaian, dan lain-lain.

2. Gunakan satuan untuk membuat urutan karakteristik klasifikasi data tersebut, seperti frekuensi, waktu, unit, rupiah, dll.

3. Kumpulkan data pada suatu periode waktu yang diteliti.

4. Buat ranking kategori data dari frekuensi yang terbesar sampai terkecil.

5. Hitung frekuensi kumulatif dan juga persentase kumulatif.

6. Gunakan diagram batang, untuk memperlihatkan tingkat kepentingan (prioritas) relatif untuk setiap masalah. Prioritas masalah utama ditempatkan di sebelah kiri pada diagram batang.

Berdasarkan Tabel 1 di atas, maka dapat dibuat frekuensi dan persentase kumulatif permasalah yang disusun pada Tabel 2.

Tabel 2. Frekuensi dan Persentase Kumulatif Permasalahan di Bagian Pemasaran Kantor Pos Bandung

\begin{tabular}{l|c|c|c|c|}
\hline \multicolumn{1}{c|}{ Jenis Permasalahan } & Frekuensi & $\begin{array}{c}\text { Akumulasi } \\
\text { Frekuensi }\end{array}$ & $\begin{array}{c}\text { Persentase } \\
\text { Dari Total }\end{array}$ & $\begin{array}{c}\text { Akumulasi } \\
\text { Persentase }\end{array}$ \\
\hline Kesalahan External ID & 48 & 48 & $44,4 \%$ & $44,4 \%$ \\
\hline Kesalahan Penginputan Alamat Penerima & 33 & 81 & $30,5 \%$ & $75 \%$ \\
\hline Kesalahan Penginputan Biaya HTNB & 17 & 98 & $15,8 \%$ & $91 \%$ \\
\hline Piutang Macet & 10 & 108 & $9,3 \%$ & $100 \%$ \\
\hline \multicolumn{1}{c|}{ Total } & 108 & & $100 \%$ & \\
\hline
\end{tabular}

Selanjutnya berdasarkan Tabel 2, maka dapat digambarkan Diagram Pareto sebagai berikut :

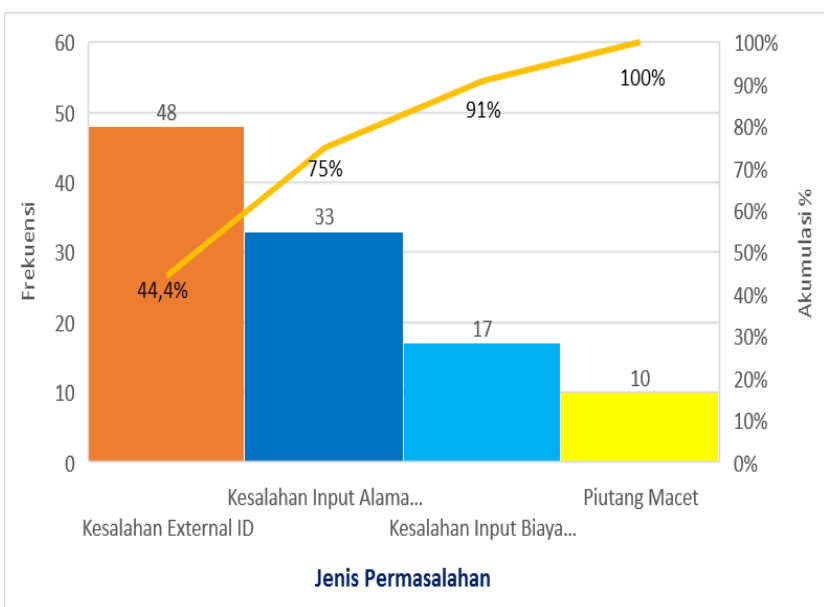

Gambar 1. Diagram Pareto Permasalahan di Bagian Pemasaran Kantor Pos Bandung

Gambar Diagram Pareto di atas memperlihatkan bahwa Kesalahan External ID merupakan permasalahan utama yang menjadi prioritas utama untuk dilakukan analisis perbaikan.

\subsection{Analysis}

Diagram Sebab-Akibat digunakan Tools untuk analisis Kesalahan External ID yang menjadi prioritas utama untuk dilakukan analisis perbaikan. Menurut Heizer, J., Render, B., dan Munson, C. (2017), Fishbone Diagram atau Ishikawa Diagram atu Diagram Sebab memperlihatkan masalaha utama yang akan diperbaiki dan faktor-faktor utama yang menyebabkan terjadinya masalah utam tersebut. Faktor-faktpr utama digambarkan sebagai tulang ikan yang mewakili kemungkinan sumber penyebab kesalahan. Fishbone Diagram untuk Kesalahan External ID digambarkan sebagai berikut:

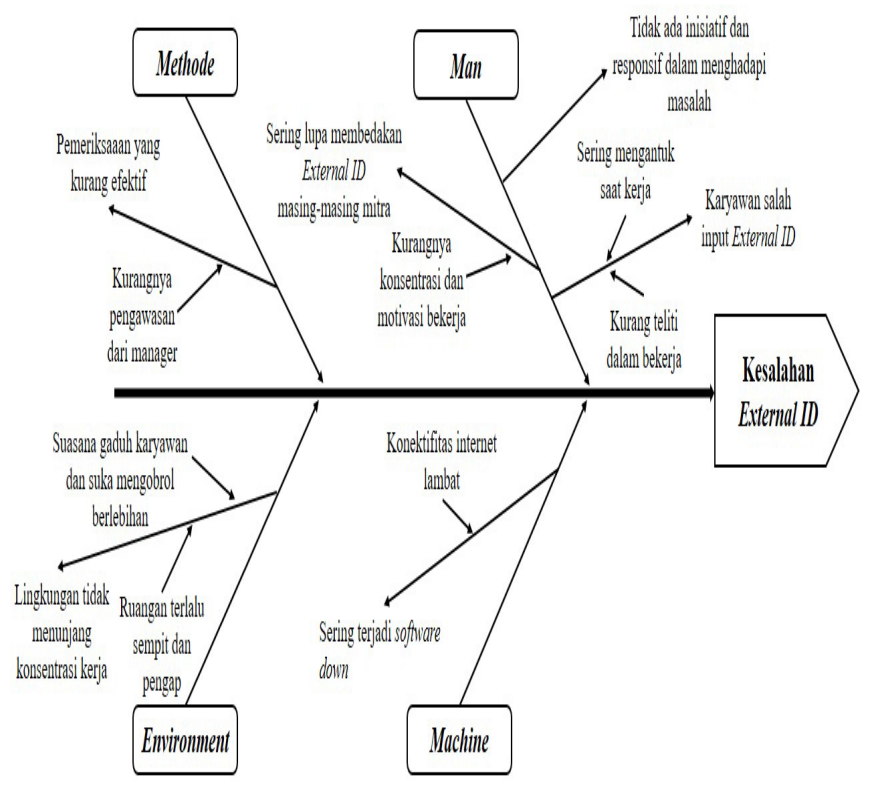

Gambar 2. Fishbone Diagram Kesalahan External ID di Bagian Pemasaran Kantor Pos Bandung

Berdasarkan Fishbone Diagram di atas maka dapat dilakukan analisis yang dijelaskan pada Tabel 3 . 
Tabel 3. Analisis Diagram Fishbone Kesalahan External Id

\begin{tabular}{|c|c|c|c|}
\hline $\begin{array}{c}\text { Identifikasi } \\
\text { Masalah }\end{array}$ & $\begin{array}{c}\text { Faktor } \\
\text { Penyebab } \\
\text { Masalah }\end{array}$ & Akar Permasalahan & Dampak Dari Akar Permasalahan \\
\hline \multirow{4}{*}{$\begin{array}{l}\text { Kesalahan } \\
\text { external id }\end{array}$} & \multirow{3}{*}{ Man } & $\begin{array}{l}\text { Tidak ada inisiatif } \\
\text { dan responsif } \\
\text { dalam menghadapi } \\
\text { masalah }\end{array}$ & $\begin{array}{l}\text { Banyak customer complaint yang } \\
\text { masuk ke perusahaan terkait External } \\
\text { Id yang salah }\end{array}$ \\
\hline & & $\begin{array}{l}\text { Karyawan salah } \\
\text { input externa } 1 \text { id }\end{array}$ & $\begin{array}{l}\text { Kurang telitinya karyawan dalam } \\
\text { bekerja, sering mengantuknya } \\
\text { karyawan pada saat jam siang. Kejadian } \\
\text { seperti ini sering kali berulang-ulang } \\
\text { karena penyebab human error. }\end{array}$ \\
\hline & & $\begin{array}{l}\text { Karyawan sering } \\
\text { lupa membedakan } \\
\text { externa } 1 \text { id } \\
\text { masing-masing }\end{array}$ & $\begin{array}{l}\text { Karyawan lupa kode external id } \\
\text { karena kurangnya konsentrasi dan } \\
\text { motivasi karyawan dalam melakukan } \\
\text { pekerjaaan. }\end{array}$ \\
\hline & Methode & $\begin{array}{l}\text { Pemeriksaan yang } \\
\text { kurang efektif }\end{array}$ & $\begin{array}{l}\text { Kurangnya pengawasan dari Manager } \\
\text { mengakibatkan proses kerja karyawan } \\
\text { tidak terkendali dengan baik dan } \\
\text { membuat banyaknya complaint dari } \\
\text { customer. Meningkatnya complain } \\
\text { dari customer membuat kualitas } \\
\text { pelayanan jasa menjadi berkurang } \\
\text { dalam sudut pandangan customer } \\
\text { perusahaan. }\end{array}$ \\
\hline \multirow[t]{2}{*}{$\begin{array}{l}\text { Kesalahan } \\
\text { external id }\end{array}$} & $\begin{array}{l}\text { Environ- } \\
\text { ment }\end{array}$ & $\begin{array}{l}\text { Lingkungan tidak } \\
\text { menunjang } \\
\text { konsentrasi kerja }\end{array}$ & $\begin{array}{l}\text { Ruangan kerja yang terlalu sempit dan } \\
\text { pengap, antar karyawan suka } \\
\text { mengobrol berlebihan serta suasana } \\
\text { gaduh antar karyawan yang tidak } \\
\text { terkontrol membuat lingkungan } \\
\text { ruangan tidak menunjang konsentrasi } \\
\text { dalam bekerja. Jika tidak konsentrasi, } \\
\text { hal ini yang biasanya karyawan salah } \\
\text { dalam penginputan External ID, } \\
\text { sehingga membuat data salah dan tidak } \\
\text { sesuai dengan harapan customer }\end{array}$ \\
\hline & Machine & $\begin{array}{l}\text { Sering terjadinya } \\
\text { software down }\end{array}$ & $\begin{array}{l}\text { Konektifitas internet yang sering } \\
\text { lambat mengakibatkan sistem software } \\
\text { mengalami down dan error. Ini akan } \\
\text { mengakibatkan penginputan Kode } \\
\text { external id yang dilakukan terganggu. }\end{array}$ \\
\hline
\end{tabular}

\subsection{Improve}

Improve merekomendasikan tindakan atau solusi masalah dengan menggunakan $5 \mathrm{~W}+1 \mathrm{H}$ dengan menjelaskan rencana tindakan meliputi (1) What, apa target utama perbaikan; (2) Why, mengapa diperlukan perbaikan mutu; (3) Where, dimanaa pelaksanaannya; (4) Who, siapa yang terlibat; (5) When, kapan dilaksanaka; dan (6) How, bagaimana mengerjakannya. Selanjutnya Analisis Improve untuk perbaikan dari permasalahan Kesalahan input External Id dijelaskan pada Tabel 4.
Tabel 4. Analisis Improve dengan $5 \mathrm{~W}+1 \mathrm{H}$

\begin{tabular}{|c|c|c|c|c|}
\hline No & Faktor & $5 \mathrm{~W}+1 \mathrm{H}$ & Deskripsi & Tindakan \\
\hline \multirow{18}{*}{1} & \multirow{6}{*}{$\begin{array}{l}\text { Faktor : Man } \\
\text { Tidak ada } \\
\text { inisiatif dan } \\
\text { responsif } \\
\text { dalam } \\
\text { menghadapi } \\
\text { masalah }\end{array}$} & What & $\begin{array}{l}\text { Apa yang menjadi } \\
\text { target utama dari } \\
\text { perbaikan kualitas? }\end{array}$ & $\begin{array}{l}\text { Meningkatkan inisiatif dan responsive karyawan } \\
\text { terhadap permasalahan yang dihadapi }\end{array}$ \\
\hline & & Why & $\begin{array}{l}\text { Mengapa rencana } \\
\text { tindakan diperlukan? }\end{array}$ & $\begin{array}{l}\text { Karena banyaknya customer complaint yang } \\
\text { masuk ke perusahaan terkait external ID yang } \\
\text { salah. }\end{array}$ \\
\hline & & Where & \begin{tabular}{|l|} 
Dimana rencana \\
tersebut dilaksanakan?
\end{tabular} & Di bagian Pemasaran. \\
\hline & & When & $\begin{array}{l}\text { Kapan tindakan ini akan } \\
\text { dilaksanakan? }\end{array}$ & $\begin{array}{l}\text { Sebaiknya perbaikan segera dilakukan untuk } \\
\text { mencegah dan meminimalisir kejadian serupa } \\
\text { terulang kembali }\end{array}$ \\
\hline & & Who & $\begin{array}{l}\text { Siapa yang akan } \\
\text { mengerjakan aktivitas } \\
\text { rencana itu? }\end{array}$ & Manajer Penjualan dan Staff pemasaran \\
\hline & & How & $\begin{array}{l}\text { Bagaimana } \\
\text { mengerjakan rencana } \\
\text { tersebut? }\end{array}$ & $\begin{array}{l}\text { Sebelum melakukan aktivitas kerja, manajer } \\
\text { harus melakukan briefing terlebih dahulu kepada } \\
\text { seluruh staff pemasaran, serta semua staff harus } \\
\text { menanamkan jiwa saling care dan rasa inisiatif } \\
\text { agar kejadian tersebut tidak terulang lagi. }\end{array}$ \\
\hline & \multirow{6}{*}{$\begin{array}{l}\text { Faktor : Man } \\
\text { Karyawan } \\
\text { salah input } \\
\text { External ID }\end{array}$} & What & $\begin{array}{l}\text { Apa yang menjadi } \\
\text { target utama dari } \\
\text { perbaikan kualitas? }\end{array}$ & $\begin{array}{l}\text { Untuk mencegah dan meminimalisir kejadian } \\
\text { salah input external ID agar tidak salah bahkan } \\
\text { jangan pernah melakukan kesalahan input } \\
\text { external ID lagi. }\end{array}$ \\
\hline & & Why & $\begin{array}{l}\text { Mengapa rencana } \\
\text { tindakan diperlukan? }\end{array}$ & $\begin{array}{l}\text { Karena ketika petugas salah input kode external } \\
\text { ID ini akan membuat dokumen seperti } \\
\text { backsheet, neraca serta data disistem nya salah. }\end{array}$ \\
\hline & & Where & $\begin{array}{l}\text { Dimana rencana } \\
\text { tersebut dilaksanakan? }\end{array}$ & Di bagian Pemasaran. \\
\hline & & When & $\begin{array}{l}\text { Kapan tindakan ini akan } \\
\text { dilaksanakan? }\end{array}$ & $\begin{array}{l}\text { Pada proses penginputan data kiriman ke Ipos- } \\
\text { Web }\end{array}$ \\
\hline & & Who & $\begin{array}{l}\text { Siapa yang akan } \\
\text { mengerjakan aktivitas } \\
\text { rencana itu? }\end{array}$ & Manager dan Staff pemasaran \\
\hline & & How & $\begin{array}{l}\text { Bagaimana } \\
\text { mengerjakan rencana } \\
\text { tersebut? }\end{array}$ & $\begin{array}{l}\text { Manager harus melakukan rapat divisi minimal } 1 \\
\text { minggu sekali, atau evaluasi setiap hari selesai } \\
\text { bekerja. Juga diperlukan sanksi yang tegas } \\
\text { ataupun reward kepada karyawan. }\end{array}$ \\
\hline & \multirow{6}{*}{$\begin{array}{l}\text { Faktor : Man } \\
\text { Karyawan } \\
\text { sering lupa } \\
\text { membedakan } \\
\text { External ID } \\
\text { masing- } \\
\text { masing mitra }\end{array}$} & What & $\begin{array}{l}\text { Apa yang menjadi } \\
\text { target utama dari } \\
\text { perbaikan kualitas? }\end{array}$ & $\begin{array}{l}\text { Untuk mencegah dan bahkan jangan sampai } \\
\text { terulang lagi kejadian yang disebabkan human } \\
\text { error ini seperti lupa kode external id. }\end{array}$ \\
\hline & & Why & $\begin{array}{l}\text { Mengapa rencana } \\
\text { tindakan diperlukan? }\end{array}$ & $\begin{array}{l}\text { Karena jika lupa akan kode external id } \text { akan } \\
\text { membuat proses penginputan data kiriman } \\
\text { terganggu dan proses keria tidak efektif. }\end{array}$ \\
\hline & & Where & \begin{tabular}{|l|} 
Dimana rencana \\
tersebut dilaksanakan? \\
\end{tabular} & Di Bagian Pemasaran \\
\hline & & When & $\begin{array}{l}\text { Kapan tindakan ini akan } \\
\text { dilaksanakan? }\end{array}$ & $\begin{array}{l}\text { Pada proses penginputan data kiriman ke Ipos- } \\
W e b\end{array}$ \\
\hline & & Who & $\begin{array}{l}\text { Siapa yang akan } \\
\text { mengerjakan aktivitas } \\
\text { rencana itu? }\end{array}$ & Staff pemasaran \\
\hline & & How & $\begin{array}{l}\text { Bagaimana } \\
\text { mengerjakan rencana } \\
\text { tersebut? }\end{array}$ & $\begin{array}{l}\text { Staff pemasaran seharusnya lebih konsentrasi } \\
\text { lagi dalam bekerja agar kesalahan yang berulang } \\
\text { tidak terjadi. Harus lebih sering mengenal } \\
\text { permasalahan yang dulu sering terjadi. Dan } \\
\text { membuat daftar kode external id masing-masing } \\
\text { mitra dan ditempel didekat ruangan penginputan } \\
\end{array}$ \\
\hline & \multirow{6}{*}{$\begin{array}{l}\text { Faktor : } \\
\text { Methode } \\
\text { Pemeriksaan } \\
\text { yang kurang } \\
\text { efektif }\end{array}$} & What & $\begin{array}{l}\text { Apa yang menjadi } \\
\text { target utama dari } \\
\text { perbaikan kualitas? }\end{array}$ & $\begin{array}{l}\text { Diharapkan semakin adanya pengawasan dari } \\
\text { Manager agar lebih terkendali lagi proses kerja } \\
\text { karyawan, sehingga tidak mengakibatkan } \\
\text { kesalahan dalam external id. } \\
\end{array}$ \\
\hline & & Why & \begin{tabular}{|l|} 
Mengapa rencana \\
tindakan diperlukan?
\end{tabular} & $\begin{array}{l}\text { Kualitas pelayanan jasa menjadi berkurang dalam } \\
\text { sudut pandang customer } \text { perusahaan. }\end{array}$ \\
\hline & & Where & \begin{tabular}{|l|} 
Dimana rencana \\
tersebut dilaksanakan?
\end{tabular} & Di bagian Pemasaran. \\
\hline & & When & $\begin{array}{l}\text { Kapan tindakan ini akan } \\
\text { dilaksanakan? }\end{array}$ & Saat proses kerja staff pemasaran. \\
\hline & & Who & \begin{tabular}{|l|} 
Siapa yang akan \\
mengerjakan aktivitas \\
rencana itu?
\end{tabular} & Manager Pemasaran \\
\hline & & How & $\begin{array}{l}\text { Bagaimana } \\
\text { mengerjakan rencana } \\
\text { tersebut? }\end{array}$ & $\begin{array}{l}\text { Manager Pemasaran secara berkala tiap hari } \\
\text { dapat lebih melakukan pengawasan dan menjadi } \\
\text { partner yang memberikan solusi solusi bagi } \\
\text { staff dalam proses kerja. }\end{array}$ \\
\hline
\end{tabular}


Lanjutan Tabel 4. Analisis Improve dengan $5 \mathrm{~W}+1 \mathrm{H}$

\begin{tabular}{|c|c|c|c|c|}
\hline No & Faktor & $5 \mathrm{~W}+1 \mathrm{H}$ & Deskripsi & Tindakan \\
\hline & \multirow{6}{*}{\begin{tabular}{|l} 
Faktor : \\
Environment \\
Lingkungan \\
tidak \\
menunjang \\
konsentrasi \\
kerja
\end{tabular}} & What & $\begin{array}{l}\text { Apa yang menjadi } \\
\text { target utama dari } \\
\text { perbaikan kualitas? }\end{array}$ & $\begin{array}{l}\text { Membuat lingkungan kerja agar lebih kondusif } \\
\text { dan nyaman dalam bekerja. }\end{array}$ \\
\hline & & Why & $\begin{array}{l}\text { Mengapa rencana } \\
\text { tindakan diperlukan? }\end{array}$ & $\begin{array}{l}\text { Karyawan kurang konsentrasi dalam bekerja } \\
\text { terurtama dalam proses penginputan data kiriman } \\
\text { customer. }\end{array}$ \\
\hline & & Where & $\begin{array}{l}\text { Dimana rencana } \\
\text { tersebut dilaksanakan? }\end{array}$ & Di Bagian Pemasaran \\
\hline & & When & $\begin{array}{l}\text { Kapan tindakan ini akan } \\
\text { dilaksanakan? }\end{array}$ & $\begin{array}{l}\text { Setiap saat dalam proses kerja bagian Pemasaran } \\
\text { agar lingkungan nyaman dan proses kerja aman. }\end{array}$ \\
\hline & & Who & \begin{tabular}{|l|} 
Siapa yang akan \\
mengerjakan aktivitas \\
rencana itu?
\end{tabular} & $\begin{array}{l}\text { Manager Penjualan, Staff Pemasaran, dan } \\
\text { seluruh karyawan perusahaan. }\end{array}$ \\
\hline & & How & $\begin{array}{l}\text { Bagaimana } \\
\text { mengerjakan rencana } \\
\text { tersebut? }\end{array}$ & $\begin{array}{l}\text { Membuat lingkungan yang nyaman agar lebih } \\
\text { konsentrasi dalam bekerja, saling menghargai } \\
\text { serta membuat peraturan yang harus disepakati } \\
\text { bersama semua karyawan perusahaan dalam } \\
\text { ruangan saat proses keria. }\end{array}$ \\
\hline & \multirow{7}{*}{$\begin{array}{l}\text { Faktor: } \\
\text { Machine } \\
\text { Sering } \\
\text { terjadinya } \\
\text { software } \\
\text { down }\end{array}$} & What & \begin{tabular}{|l} 
Apa yang menjadi \\
target utama dari \\
perbaikan kualitas?
\end{tabular} & $\begin{array}{l}\text { Agar konektifitas jaringan internet lancar serta } \\
\text { tidak kejadian lagi software down dan error. }\end{array}$ \\
\hline & & Why & $\begin{array}{l}\text { Mengapa rencana } \\
\text { tindakan diperlukan? }\end{array}$ & $\begin{array}{l}\text { Menyebabkan penginputan data kiriman kesistem } \\
\text { Ipos-Web yang dilakukan terganggu dan tidak } \\
\text { dapat dilakukan sama sekali. }\end{array}$ \\
\hline & & Where & \begin{tabular}{|l|} 
Dimana rencana \\
tersebut dilaksanakan?
\end{tabular} & Di Bagian Pemasaran \\
\hline & & When & $\begin{array}{l}\text { Kapan tindakan ini akan } \\
\text { dilaksanakan? }\end{array}$ & $\begin{array}{l}\text { Pada proses penginputan data kiriman ke Ipos- } \\
\text { Web }\end{array}$ \\
\hline & & Who & $\begin{array}{l}\text { Siapa yang akan } \\
\text { mengerjakan aktivitas } \\
\text { rencana itu? }\end{array}$ & $\begin{array}{l}\text { Manager Pemasaran melakukan koordinasi } \\
\text { dengan bagian Jaringan Teknologi (IT) }\end{array}$ \\
\hline & & \multirow[t]{2}{*}{ How } & \multirow[t]{2}{*}{$\begin{array}{l}\text { Bagaimana } \\
\text { mengerjakan rencana } \\
\text { tersebut? }\end{array}$} & $\begin{array}{l}\text { - Peningkatan software versi lama yang lebih } \\
\text { efisien dan efektif dalam memproses } \\
\text { penginputan data kiriman. Mengevaluasi atau } \\
\text { mengecek secara berkala jaringan internet. }\end{array}$ \\
\hline & & & & $\begin{array}{l}\text { - Menambahkan jaringan wifi disetiap ruangan } \\
\text { lantai atas dan bawah agar jaringan stabil }\end{array}$ \\
\hline
\end{tabular}

\subsection{Control}

Dalam tahap control, lanjutkan pencapaian yang telah dicapai dari tahap improve. Desain kebutuhan pengendalian untuk mempertahankan pencapaian yang telah dicapai dan terus lakukan pengawasan. Dalam mengurangi permasalahan yang terjadi yaitu kesalahan external id, karyawan telah melakukan salah satu rekomendasi perbaikan yaitu membuat catatan yang berisi kode external id. Cara ini dibuat agar mempermudah karyawan dalam menginput data kiriman agar tidak lupa maupun salah dalam penginputan external id.

\subsection{Rekomendasi Perbaikan}

Berdasarkan hasil analisis menggunakan metode DMAIC untuk persoalan di atas, maka rekomendasi untuk perbaikan pada proses kerja di Bagian Pemasaran Kantor Pos Bandung disajikan pada Tabel 5.
Tabel 5. Rekomendasi perbaikan pada proses kerja di Bagian Pemasaran Kantor Pos Bandung

\begin{tabular}{|c|c|c|c|c|}
\hline No & $\begin{array}{c}\text { Akar } \\
\text { Masalah }\end{array}$ & Deskripsi & Solusi & Alasan \\
\hline 1. & Man & $\begin{array}{l}\text { Masih kurangnya } \\
\text { peran staf untuk } \\
\text { meminimalisir } \\
\text { permasalahan, } \\
\text { input external id }\end{array}$ & $\begin{array}{l}\text { - Manajer memberikan } \\
\text { briefing sebelum memulai } \\
\text { pekerjaan. } \\
\text { - Rapat divisi minimal } 1 \\
\text { minggu sekali, atau } \\
\text { evaluasi setiap selesai jam } \\
\text { kerja. } \\
\text { - Pemberian sanksi atau } \\
\text { reward. } \\
\text { - Membuat daftar kode } \\
\text { external id masing-masing } \\
\text { mitra dan ditempel didekat } \\
\text { ruangan penginputan. }\end{array}$ & $\begin{array}{l}\text { - Agar tahu akan } \\
\text { keluhan yang dihadapi } \\
\text { karyawan } \\
\text { - Muncul strategi } \\
\text { strategi baru bagi } \\
\text { perbaikan kinerja } \\
\text { unit bagian Pemasaran } \\
\text { - Termotivasi semakin } \\
\text { lebih baik dalam } \\
\text { melakukan pekerjaan. } \\
\text { - Agar lebih mudah } \\
\text { dalam proses } \\
\text { penginputan data } \\
\text { kirirman. }\end{array}$ \\
\hline 2. & Methode & $\begin{array}{l}\text { Pemeriksaan yang } \\
\text { kurang efektif } \\
\text { oleh Manajer }\end{array}$ & $\begin{array}{l}\text { Manajer secara berkala tiap } \\
\text { hari melakukan pengawasan } \\
\text { agar dapat menjadi partner } \\
\text { yang memberikan solusi bagi } \\
\text { staff dalam proses kerja. }\end{array}$ & $\begin{array}{l}\text { Agar proses kerja } \\
\text { karyawan lebih } \\
\text { terkendali dan terkontrol. }\end{array}$ \\
\hline 3. & Environment & $\begin{array}{l}\text { Lingkungan } \\
\text { tempat kerja yang } \\
\text { tidak kondusif } \\
\text { untuk konsentrasi } \\
\text { kerja }\end{array}$ & $\begin{array}{l}\text { Saling menghargai dan } \\
\text { membuat peraturan yang } \\
\text { disepakati bersama saat } \\
\text { proses kerja }\end{array}$ & $\begin{array}{l}\text { Meningkatnya } \\
\text { produktifitas karyawan } \\
\text { dan dapat meminimalisir } \\
\text { kelalaian saat kerja. }\end{array}$ \\
\hline 4. & Machine & $\begin{array}{l}\text { Sering terjadinya } \\
\text { software down } \\
\text { dan konektifitas } \\
\text { jaringan internet } \\
\text { yang lambat }\end{array}$ & $\begin{array}{l}\text { - Mengevaluasi atau } \\
\text { mengecek secara berkala } \\
\text { jaringan internet. } \\
\text { - Menambahkan kapasitas } \\
\text { bandwidth dan jaringan } \\
\text { wifi disetiap ruangan lantai } \\
\text { atas dan bawah agar } \\
\text { jaringan stabil. }\end{array}$ & $\begin{array}{l}\text { - Pekerjaan menjadi } \\
\text { semakin cepat, efektif. } \\
\text { dan efisien. } \\
\text { - Agar tidak ada kendala } \\
\text { jaringan dan konekssi } \\
\text { lambat dalam proses } \\
\text { input data kiriman }\end{array}$ \\
\hline
\end{tabular}

\section{KESIMPULAN}

Kesimpulan penelitain perbaikan proses kerja di Bagian Pemasaran Kantor Pos Bandung dengan menggunakan metode DMAIC, adalah sebagai berikut :

1. Permasalahan yang menjadi prioritas utama untuk diperbaiki yaitu Kesalahan External id pada penginputan ke Ipos-Web sehingga berdampak dengan ketidakpuasan konsumen dan juga permasalahan di neraca, backsheet maupun tagihan yang akan dilakukan oleh PT Pos Indonesia.

2. Penyebab utama Kesalahan External id yaitu faktor man dimana staf kurang inisiatif dan responsif dalam menghadapi permasalahan yang terjadi, kurang teliti dan sering mengantuk saat kerja, kurangnya konsentrasi dalam bekerja membuat karyawan lupa kode external id dalam proses penginputan.

3. Secara keseluruhan, upaya yang perlu dilakukan untuk memperbaiki Kesalahan External id yaitu : perlunya peningkatan peran Manajer dalam melakukan 
pengawasan kerja, perlunya briefing sebelum pekerjaan dimulai, adanya reward dan punishment untuk meningkatkan produktivitas staf, membuat daftar Kode External Id Customer yang ditempatkan di meja entri komputer, serta peningkatan kapasitas bandwith dan perluasan akses internet.

\section{REFERENSI}

[1] Gaspersz, Vincent. Total Quality Management. Jakarta: PT. Gramedia Pustaka Utama. 2005.

[2] Pyzdek, T. The Six Sigma Handbook, New York: McGraw-Hill. (2000).

[3] Heizer, J., Render, B., and Munson, C.. Operations Management : Sustainability and Supply Chain Management. $12^{\text {th }}$ edition. Pearson Education : Boston. 2017
[4] Kumar, S., \& Sosnoski, M. Using DMAIC Six Sigma to systematically improve shopfloor production quality and costs, International Journal of Productivity and Performance Management. 2009; 58(3), 254-273.

[5] Mehrjerdi, Y. Z. Six Sigma: Methodology, tools and its future. Assembly Automation. 2011; 31 (1), $79-88$.

[6] Pusporini, P., Andesta, D. Integrasi Model Lean Sigma Untuk Peningkatan Kualitas Produk. Jurnal Teknik Industri. 2009; Vol. 10,No.2: 91-97.

[7] Sokovic, M., Pavletic, D., \& Pipan, K. K. Quality improvement methodologies - PDCA cycle, RADAR matrix, DMAIC and DFSS. Journal of Achievements in Materials and Manufacturing Engineering. 2010; 43(1), 476-483.

[8] Vanany, I. dan Emilasari, D. Aplikasi Six Sigma pada Produk Clear File di Perusahaan Stationary. Jurnal Teknik Industri. 2007; Vol. 9 No. 1,: 27-36. 